\title{
Response of fibroblast growth factor 19 and bile acid synthesis after a body weight-adjusted oral fat tolerance test in overweight and obese NAFLD patients: a non-randomized controlled pilot trial
}

\author{
Dana Friedrich ${ }^{1 *}$ DD, Hanns-Ulrich Marschall ${ }^{2}$ and Frank Lammert ${ }^{1}$
}

\begin{abstract}
Background: Non-alcoholic fatty liver disease (NAFLD) is common both in obese and overweight patients. Fibroblast growth factor 19 (FGF19), an intestinal hormone, could play a role in the complex pathogenesis of NAFLD. The aim of our study was to investigate responses of FGF19 and bile acid (BA) synthesis after a body weight-adjusted oral fat tolerance test (OFTT) in overweight and obese NAFLD patients.
\end{abstract}

Methods: For this study, we recruited 26 NAFLD patients; 14 overweight (median BMl $28.3 \mathrm{~kg} / \mathrm{m}^{2}$ ), 12 obese $\left(35.3 \mathrm{~kg} / \mathrm{m}^{2}\right)$ and 16 healthy controls $\left(24.2 \mathrm{~kg} / \mathrm{m}^{2}\right)$. All individuals received $1 \mathrm{~g}$ fat (Calogen $\left.{ }^{\oplus}\right)$ per $\mathrm{kg}$ body weight orally. Serum concentrations of FGF19 were determined by ELISA. Concentrations of BAs and BA synthesis marker 7a-hydroxy-4-cholesten-3-one (C4) were measured by gas chromatography-mass spectrometry and high-performance liquid chromatography, respectively; all at 0 (baseline), 2, 4 and $6 \mathrm{~h}$ during the OFTT.

Results: BMI correlated negatively with fasting FGF19 concentrations (rho $=-0.439, p=0.004$ ). FGF19 levels of obese NAFLD patients were significantly ( $p=0.01$ ) lower in the fasting state (median $116.0 \mathrm{vs} .178 .5 \mathrm{pg} / \mathrm{ml}$ ), whereas overweight NAFLD patients had significantly ( $p=0.004$ ) lower FGF19 concentrations $2 \mathrm{~h}$ after the fat load (median $163.0 \mathrm{vs.} 244.5 \mathrm{pg} /$ $\mathrm{ml}$ ), and lowest values at all postprandial time points as compared to controls. Baseline BA concentrations correlated positively with FGF19 values (rho $=0.306, p=0.048$ ). In all groups, we observed BA increases during the OFTT with a peak at $2 \mathrm{~h}$ but no change in C4 levels in overweight/obese NAFLD patients.

Conclusions: Reduced basal gastrointestinal FGF19 secretion and decreased postprandial response to oral fat together with blunted effect on BA synthesis indicate alterations in intestinal or hepatic FXR signaling in overweight and obese NAFLD subjects. The precise mechanism of FGF19 signaling after oral fat load needs further evaluation.

Trial registration: We have registered the trial retrospectively on 30 Jan 2018 at the German clinical trials register (http://www.drks.de/), and the following number has been assigned DRKS00013942.

Keywords: Bile acids, FGF19, Non-alcoholic fatty liver disease, Oral fat tolerance test

\footnotetext{
* Correspondence: dana.friedrich@uks.eu

${ }^{1}$ Department of Medicine II, Saarland University Medical Center, Saarland

University, 66421 Homburg, Germany

Full list of author information is available at the end of the article
}

(c) The Author(s). 2018 Open Access This article is distributed under the terms of the Creative Commons Attribution 4.0 International License (http://creativecommons.org/licenses/by/4.0/), which permits unrestricted use, distribution, and reproduction in any medium, provided you give appropriate credit to the original author(s) and the source, provide a link to the Creative Commons license, and indicate if changes were made. The Creative Commons Public Domain Dedication waiver (http://creativecommons.org/publicdomain/zero/1.0/) applies to the data made available in this article, unless otherwise stated. 


\section{Background}

Obesity and fatty liver disease represent increasing medical problems in developed countries. In Germany, the prevalence of obesity increased during the years 1998 to 2011 from 18.9 to $23.3 \%$ in men and from 22.5 to $23.9 \%$ in women [1]. In the United States, $37 \%$ of adults are obese [2]. Obesity is an important risk factor of non-alcoholic fatty liver disease (NAFLD), which has been reported in 30 to $40 \%$ of adults [3, 4].

The term NAFLD is used for a wide spectrum of fatty liver diseases that starts with simple steatosis in non-alcoholic fatty liver (NAFL) that may progress to non-alcoholic steatohepatits (NASH), which is complicated by fibrosis, cirrhosis, and eventually hepatocellular carcinoma [5-7]. NAFLD is often associated with the metabolic syndrome and requires exclusion of excessive alcohol consumption as well as viral and autoimmune liver diseases [8]. NAFLD is common in obesity but also in overweight patients $[9,10]$. The pathophysiology of NAFLD is complex and still not fully defined [11, 12]. Several metabolic factors have already been identified in the development of NAFLD, including insulin resistance, diabetes mellitus and obesity.

So far there have been only few studies of the importance of gastrointestinal hormones in the pathogenesis of NAFLD [13-15]. The gastrointestinal hormone fibroblast growth factor 19 (FGF19) has emerged as a novel regulator of bile acid, carbohydrate and lipid metabolism. In human metabolic syndrome associated diseases, such as type 2 diabetes mellitus (T2DM) and NAFLD, FGF19 signaling seems to be dysregulated [16]. In animals, FGF19 transgenic mice show resistance to a high-fat diet and decreased liver triglyceride concentrations [17] while the administration of recombinant FGF19 increases the metabolic rate [18]. Accordingly, in humans with NAFLD, reduced fasting FGF19 levels were found [14, 19, 20]. Therefore, the present study focuses on the dietary regulation of FGF19 and its potential role in the pathogenesis of NAFLD.

FGF19 release in the intestine is induced by bile acids (BAs). After a meal, the entry of dietary fat in the duodenum causes gallbladder contraction and BA inflow into the intestinal lumen. The reabsorption of BAs in the terminal ileum activates the canonical BA sensor farnesoid $\mathrm{X}$ receptor (FXR), resulting in enhanced transcription and secretion of FGF19 [21, 22]. FGF19 binds on hepatocytes to the FGF receptor 4 (FGFR4) and its cofactor $\beta$ Klotho [22-24], which triggers a signaling cascade that represses cholesterol $7 \alpha$-hydroxylase (CYP7A1), the rate-limiting enzyme in BA synthesis from cholesterol [25]. 7 $\alpha$-Hydroxy-4-cholesten-3-one (C4) is an intermediate of BA synthesis, which can be measured in serum [26].
Since the role of FGF19 in the pathogenesis of human NAFLD is unknown, we studied FGF19 and hepatic downstream effects ( $\mathrm{C} 4$ and BAs) in overweight and obese NAFLD outpatients (and healthy controls) that were subjected to a body weight-adjusted oral fat tolerance test (OFTT). We determined serum concentrations of FGF19, C4 and BAs at baseline and at 2, 4 and $6 \mathrm{~h}$ after OFTT. We hypothized that FGF19 levels are lower in obese compared to overweight NAFLD patients.

We aimed to answer the following questions in this study:

1. Do fasting FGF19 serum concentrations differ between normal-weight healthy, overweight and obese NAFLD patients?

2. How does a body weight-adjusted oral fat tolerance test (OFTT) affect serum FGF19 concentrations in these populations?

3. How does a postprandial FGF19 response affect hepatic BA biosynthesis, as assessed by $\mathrm{C} 4$ ?

\section{Methods \\ Study protocol}

The study protocol was approved by the Ethics Committee of the Ärztekammer des Saarlandes, Saarbrücken (ID number 58/09). All subjects ( $\geq 18$ years) were fully informed about the study objectives and methods and gave their written informed consent before participating in this non-randomized controlled pilot trial.

\section{Study subjects}

During 2009 and 2010, we recruited overweight and obese NAFLD outpatients in the Department of Internal Medicine II, Saarland University Medical Center, Homburg, as well as healthy controls with normal body weight. Inclusion criteria for NAFLD were ultrasound and/or biopsy findings consistent with fatty liver disease. Exclusion criteria were increased alcohol consumption in medical history and the following acute and chronic liver diseases: cirrhosis, hepatitis A virus (HAV), hepatitis $B$ virus $(\mathrm{HBV})$, hepatitis $\mathrm{C}$ virus $(\mathrm{HCV})$, hepatitis $\mathrm{D}$ virus (HDV), cytomegalovirus (CMV) and Epstein-Barr Virus (EBV) infections, hemochromatosis, Wilson's disease, $\alpha_{1}$-antitrypsin deficiency, and autoimmune hepatitis. Healthy controls included employees of the clinic and medical students with normal BMI and no diseases in history. In controls, no liver and laboratory diagnosis was performed.

Subjects were divided into three groups according to their BMI (healthy controls, normal weight: 19.0$25.4 \mathrm{~kg} / \mathrm{m}^{2}$, overweight NAFLD: $25.5-29.9 \mathrm{~kg} / \mathrm{m}^{2}$, obese NAFLD: $\geq 30.0 \mathrm{~kg} / \mathrm{m}^{2}$ ) $[27,28]$. 


\section{Liver parameters}

In overweight and obese patients $(N=26)$, liver status was assessed by abdominal ultrasound and/or liver biopsy. Ultrasound was performed using the Hitachi EUB-8500 ultrasound scanner (Hitachi Medical Systems, Wiesbaden, Germany). Hepatic steatosis results in abnormal echo patterns on ultrasound scanning; the severity of steatosis was graded as mild (I), moderate (II), or severe (III) [29]. Liver biopsy samples of five patients were examined by an experienced pathologist of Saarland University Medical Center.

\section{Oral fat tolerance test (OFTT)}

We used a body weight-adjusted OFTT to investigate postprandial FGF19, BA and C4 responses in our study subjects. For the present study, a standardized test drink Calogen ${ }^{\circ}$ (Nutricia, Erlangen, Germany) was administered, which is a lipid emulsion based on vegetable fat with 50\% long-chain triglycerides [30]. All individuals received $1 \mathrm{~g}$ fat per $\mathrm{kg}$ body weight orally. The fat load was based on subjects' body weight to adjust the OFTT to hypercaloric (especially high-fat) eating behavior of obese patients [31].

\section{Blood samples}

Blood samples were drawn from a peripheral vein at 8:00 AM after an overnight fasting and 2, 4 and $6 \mathrm{~h}$ after the oral fat challenge. Samples were centrifuged for $10 \mathrm{~min}$ at $3000 \mathrm{~g} 30 \mathrm{~min}$ after blood collection (ROTANTA 46R, Hettich, Tuttlingen, Germany). Subsequently, serum was stored in aliquots at-70 ${ }^{\circ} \mathrm{Cuntil}$ analysis.

\section{Serum FGF19, bile acid and C4 measurements}

FGF19 serum concentrations were measured in duplicate by quantitative sandwich enzyme-linked immunosorbent assay, using the FGF19 Quantikine ELISA kit (R\&D Systems, Minneapolis, USA). Serum BA concentrations were determined by gas chromatography-mass spectrometry (GCMS) [32]. 7 $\alpha$-hydroxy-4-cholesten-3-one (C4), a valid marker of bile acid biosynthesis [33], was measured by high-performance liquid chromatography (HPLC).

\section{Statistical analysis}

Data analysis was performed using SPSS (version 20.0, IBM, Ehningen, Germany). Kruskal-Wallis test was used to analyze quantitative data for differences within the cohort. For the present study with a low number of study subjects $(N<20)$, normal distributions were not expected [34]. Thus, data are expressed as medians and interquartile ranges (IQR 25-75). In addition, Mann-Whitney-U test was used to test differences between two groups. The strength of associations between two parameters was estimated using the non-parametric Spearman correlation test. Spearman's correlation coefficient is presented as rho. For the OFTT, FGF19 ${ }_{(0-6 h)}$-area under the curve (AUC) and, after correcting for baseline, the incremental AUC (FGF19-IAUC) were computed using GraphPad Prism (version 6.0, GraphPad Software, La Jolla, CA, USA). A $p$-value $<0.05$ denotes statistical significance.

\section{Results}

\section{Subject characteristics}

Table 1 summarizes the subject characteristics. A total of 42 subjects, 21 women and 21 men, were recruited for our study. Study participants were between 19 and 68 years old (median 47.0 years, IQR 28.8-53.8). Overall, we recruited 14 overweight and 12 obese NAFLD patients as well as 16 healthy controls. Sex and age did not differ between groups. Obese patients had a median BMI of $35.3 \mathrm{~kg} / \mathrm{m}^{2}$, which corresponds to obesity grade II [28].

NAFLD was diagnosed by ultrasound and/or biopsy. In overweight and obese patients, the steatosis spectrum ranged from grade I, II and III to NASH and fibrosis. In the overweight group $(N=14)$, grade I liver steatosis was

Table 1 Subject characteristics, basal and postprandial FGF19 serum concentrations

\begin{tabular}{|c|c|c|c|c|}
\hline Variables & Control & Overweight & Obesity & $p$-value \\
\hline N (men/women) & $16(7 / 9)$ & $14(8 / 6)$ & $12(6 / 6)$ & n.s. ${ }^{a}$ \\
\hline Age (years) & $29.5(24.0-53.0)$ & $49.0(38.8-57.3)$ & $48.0(37.0-57.3)$ & $0.551^{b}$ \\
\hline BMI $\left(\mathrm{kg} / \mathrm{m}^{2}\right)$ & $24.2(21.8-26.6)$ & $28.3(26.3-29.2)$ & $35.3(32.7-39.0)$ & $<0.001^{\mathrm{b}}$ \\
\hline \multicolumn{5}{|l|}{ FGF19 (pg/ml) } \\
\hline$t=0 h$ & $178.5(101.0-257.0)^{c}$ & 127.5 (70.0-161.3) & $116.0(51.0-134.3)^{c}$ & $0.01^{c}$ \\
\hline$t=2 h$ & $244.5(161.5-377.5)^{c}$ & $163.0(78.5-168.3)^{c}$ & 181.0 (85.3-393.0) & $0.004^{c}$ \\
\hline$t=4 h$ & 332.5 (202.0-590.8) & $207.0(112.5-365.0)$ & $220.0(138.8-385.3)$ & $0.445^{b}$ \\
\hline$t=6 h$ & 211.0 (165.3-296.3) & $154.0(124.0-254.0)$ & 184.5 (110.5-274.3) & $0.445^{b}$ \\
\hline
\end{tabular}

All data are given as median (interquartile range)

${ }^{\text {a } C h i-s q u a r e-t e s t ~}$

${ }^{b}$ Kruskal-Wallis-test

${ }^{c}$ Mann-Whitney-U-test 
found in six patients (43\%), grade II in five patients (36\%), and grade III in one patient (7\%). NASH was diagnosed in one and fibrosis stage II was documented in one patient. In the obese group $(N=12)$, two patients (17\%) displayed liver steatosis grade I, four patients (33\%) showed grade II, and three participants (25\%) had grade III. In this group, NASH was found in one and fibrosis stage I also in one patient. In one obese study participant, liver status could not be assessed by ultrasound. Additional file 1: Table S1 lists the comorbidities in overweight and obese NAFLD patients. In overweight patients, hypercholesterolemia and in obese patients, arterial hypertension were the dominant concomitant diseases, respectively. Controls did not take any drugs regularly. Three overweight and eight obese patients were taking medications. These included antidiabetics, antihypertensives, thyroid hormones, analgesics, proton pump inhibitors, antidepressants, non-steroidal antirheumatics, corticoidsteroids and allopurinol, respectively.

\section{Basal and postprandial FGF19 serum concentrations} In the total study group $(N=42)$, fasting FGF19 concentrations ranged from 17.0 to $392.0 \mathrm{pg} / \mathrm{ml}$ (median 133.5, IQR 82.8-190.3). Basal FGF19 values were significantly lower in obese NAFLD patients as compared to controls and tended to be lower in overweight NAFLD subjects, too (Table 1, Fig. 1). Basal FGF19 concentrations did not differ between sexes [women, median 126.0 (IQR 80.5179.0 ) vs. men, median 138.0 (IQR 93.0-204.0) pg/ml]. Interestingly, fasting FGF19 concentrations were negatively correlated with BMI (Fig. 2).

After the OFTT, FGF19 concentrations increased in controls, overweight and obese patients (Table 1, Fig. 1). Of note, overweight patients displayed lowest FGF19 concentrations at all postprandial time points. Two hours after the OFTT, FGF19 levels ranged from 10.0 to $697.0 \mathrm{pg} / \mathrm{ml}$ (median 178.0, IQR 116.5-255.5). At this time, overweight NAFLD patients showed significantly lower FGF19 levels compared with controls (Fig. 1). The FGF19 maximum was found in all three groups after $4 \mathrm{~h}$, with hormone levels ranging from 59.0 to $935.0 \mathrm{pg} /$ $\mathrm{ml}$ (median 255.0, IQR 163.3-439.3). At 4 h, FGF19 was highest in controls and twice as high as at baseline. After $6 \mathrm{~h}$, FGF19 values ranged from 48.0 to 802.0 pg/ml (median 189.0, IQR 136.0-269.0) and were still highest in controls.

Both women and men showed the FGF19 maximum at $4 \mathrm{~h}$ [women, median 270.0 (IQR 167.5-539.0) vs. men, median 231.0 (IQR 117.5-410.5) $\mathrm{pg} / \mathrm{ml}$ ] but

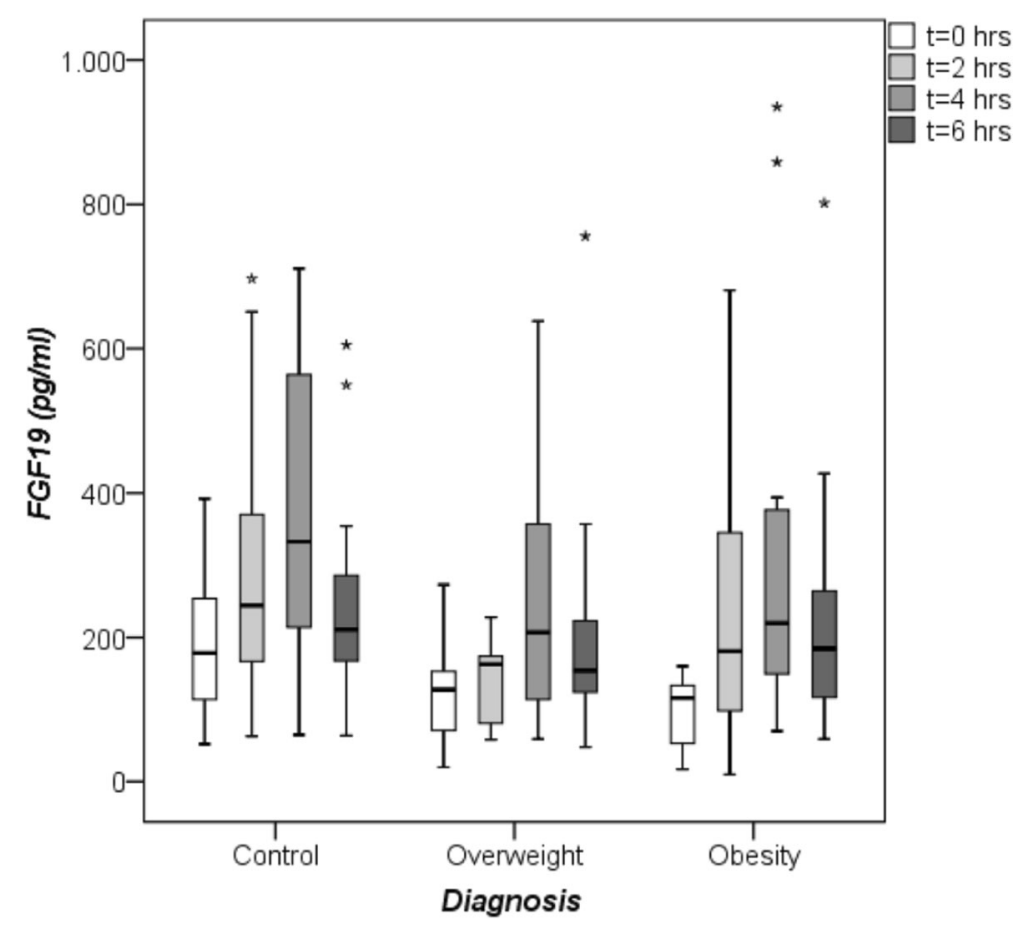

Fig. 1 Fasting and postprandial FGF19 serum concentrations measured by quantitative sandwich enzyme-linked immunosorbent assay (ELISA). Comparison of FGF19 values between healthy controls $(N=16)$, overweight $(N=14)$ and obese $(N=12)$ patients with non-alcoholic fatty liver disease (NAFLD) at baseline $(0 \mathrm{~h}), 2,4$ and $6 \mathrm{~h}$ after the oral fat tolerance test (OFTT). Significant difference between basal $(0 \mathrm{~h})$ FGF19 concentrations in controls and obese NAFLD patients [controls 178.5 (101.0-257.0) vs. obese 116.0 (51.0-134.3) pg/ml, medians (IQRs), $p=<0.05$, Mann-Whitney-U-test). At $2 \mathrm{~h}$, lower FGF19 values in overweight NAFLD patients in comparison to controls [overweight 163.0 (78.5-168.3) vs. controls 244.5 (161.5-377.5) pg/ml, medians (IQRs), $p=0.004$, Mann-Whitney-U-test), * outlier 


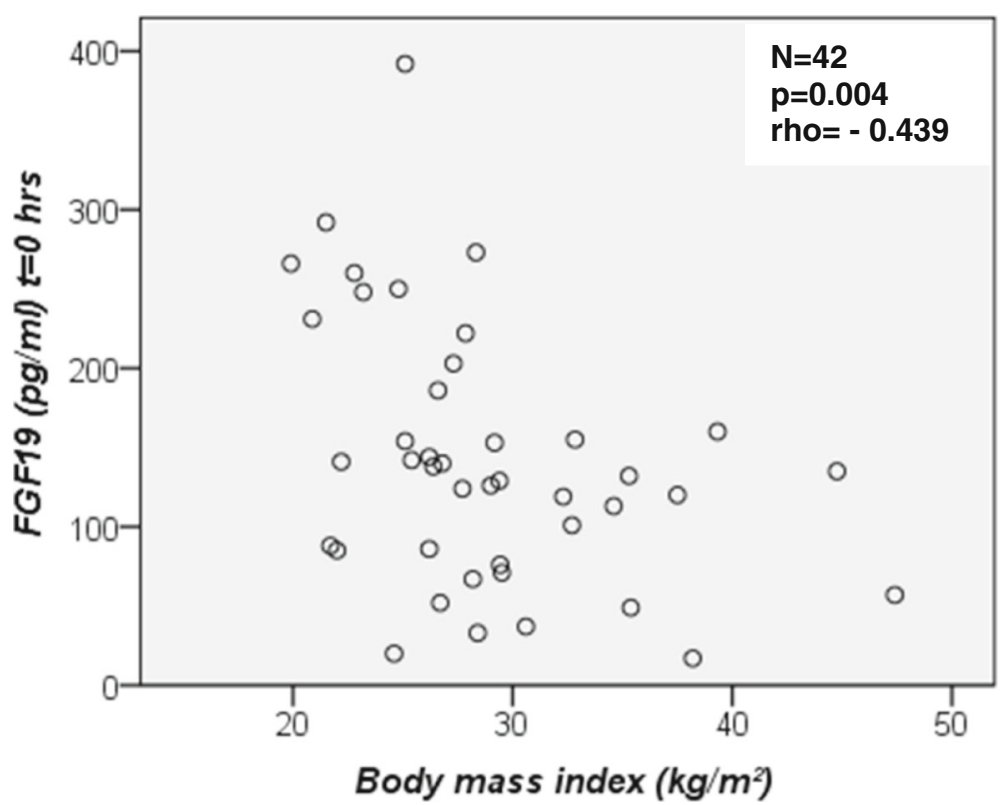

Fig. 2 Fasting FGF19 serum concentrations versus body mass index (BMI) for all study subjects. FGF19 values correlated negatively with BMI. A scattered plot is shown and the Spearman's correlation coefficient was calculated

postprandial levels were higher in women at all time points. Six hours after the oral fat challenge, FGF19 concentrations of both sexes tended to reach a significant difference [women, median 216.0 (IQR 145.0-390.5) vs. men, median 172.0 (IQR124.0-216.5) pg/ml, $p=0.051]$.

Mean FGF19(0-6h) -area and mean incremental area under the curve (AUC and IAUC) did not differ significantly between the groups (AUC controls: 1772.8 \pm 766.6 vs. overweight: $1130.6 \pm 590.0$ vs. obese: $1469.3 \pm 910.0 \mathrm{pg} / \mathrm{ml} / 6 \mathrm{~h}$; IAUC controls: $699.0 \pm 383.7 \mathrm{vs}$. overweight: $573.3 \pm 333.4$ vs. obese: $921.5 \pm 732.4 \mathrm{pg} / \mathrm{ml}$ ). FGF19-AUC was highest in controls and lowest in overweight patients $(p=0.053)$; IAUC was higher in obese and lower in overweight patients in comparison to controls. FGF19-AUC and IAUC did not correlate with body weight-adjusted fat load. In addition, there was no association between FGF19-AUC and BMI; FGF19-IAUC tended to correlate with age $(\mathrm{rho}=0.291$, $p=0.062)$.

\section{Basal and postprandial $B A$ serum concentrations}

Fasting and postprandial bile acid (BA) concentrations did not differ between overweight/obese NAFLD patients and controls. In all three groups, we observed a BA increase after the OFTT with a peak at $2 \mathrm{~h}$ (Table 2). Basal FGF19 concentrations correlated positively with basal BA values (Fig. 3).

Table 2 Basal and postprandial BA and C4 serum concentrations

\begin{tabular}{|c|c|c|c|c|}
\hline Variables & Control & Overweight & Obesity & $p$-value \\
\hline $\mathrm{N}$ (men/women) & $16(7 / 9)$ & $14(8 / 6)$ & $12(6 / 6)$ & n.s. ${ }^{a}$ \\
\hline \multicolumn{5}{|l|}{ Bile acids $(\mu \mathrm{M})$} \\
\hline$t=0 h$ & $1.1(0.8-1.7)$ & $1.5(0.8-2.2)$ & $1.4(0.9-1.7)$ & 0.343 \\
\hline$t=2 h$ & $1.4(1.1-4.7)$ & $2.1(1.2-3.8)$ & $2.4(1.6-4.1)$ & 0.311 \\
\hline$t=4 h$ & $1.1(0.7-2.0)$ & $2.0(1.3-2.5)$ & $2.0(1.0-2.3)$ & 0.155 \\
\hline$t=6 h$ & $0.7(0.5-1.6)$ & $1.3(0.8-2.0)$ & $1.2(0.8-1.7)$ & 0.087 \\
\hline \multicolumn{5}{|l|}{ C4 (nM) } \\
\hline$t=0 h$ & $41.4(7.0-69.2)$ & $58.5(12.8-91.6)$ & $35.1(1.2-72.3)$ & 0.422 \\
\hline$t=2 h$ & $28.1(7.1-49.6)$ & $43.1(10.0-114.0)$ & $35.7(1.2-118.3)$ & 0.765 \\
\hline$t=4 h$ & $13.0(6.8-44.7)$ & $40.8(21.1-99.3)$ & $32.7(3.3-108.0)$ & 0.343 \\
\hline$t=6 h$ & $11.8(4.1-34.4)$ & $40.7(18.1-80.1)$ & $28.6(3.5-82.4)$ & 0.445 \\
\hline
\end{tabular}




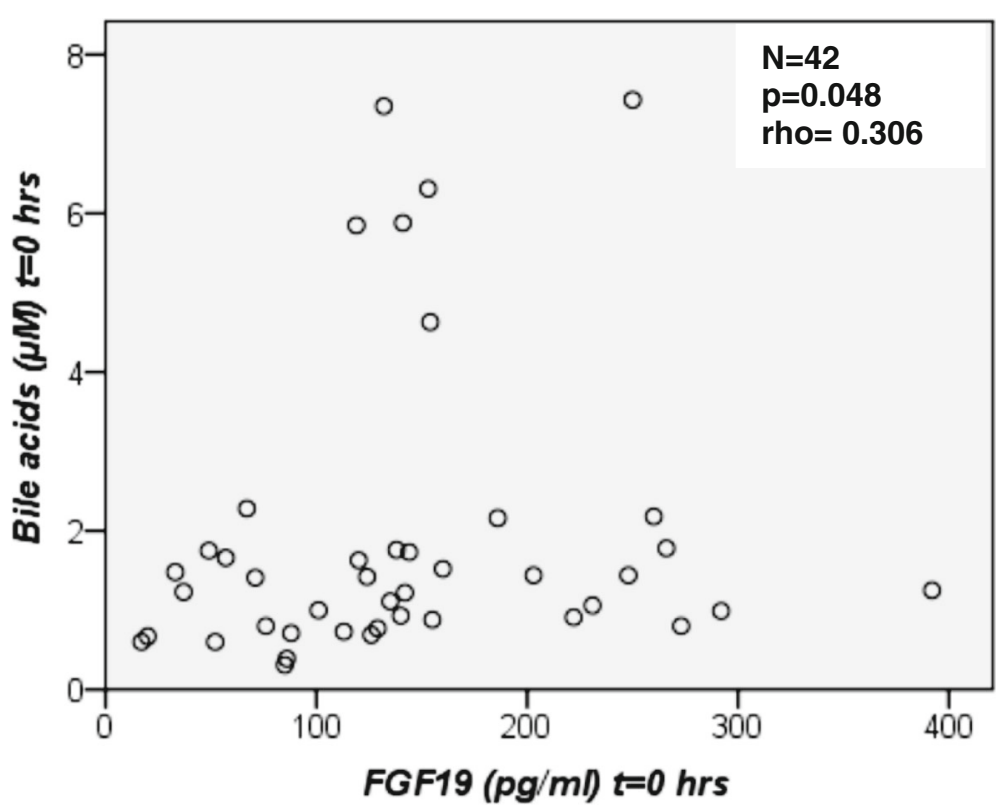

Fig. 3 Fasting FGF19 serum concentrations versus fasting bile acid (BA) serum concentrations for all subjects $(N=42)$. There was a correlation between FGF19 and BA values. A scattered plot is shown and the Spearman's correlation coefficient was calculated

\section{Basal and postprandial C4 serum concentrations}

Fasting and postprandial C4 values did not differ significantly between study participants (Table 2, Fig. 4). At all postprandial time points, $\mathrm{C} 4$ concentrations were markedly lower in controls in comparison to overweight/ obese NAFLD patients. C4 concentrations in overweight NAFLD patients remained unchanged for $4 \mathrm{~h}$ postprandially, despite increasing FGF19 values. In the total study group FGF19 concentrations at $2 \mathrm{~h}$ correlated negatively with $\mathrm{C} 4$ values at $4 \mathrm{~h}$ after the OFTT (Fig. 5). There was

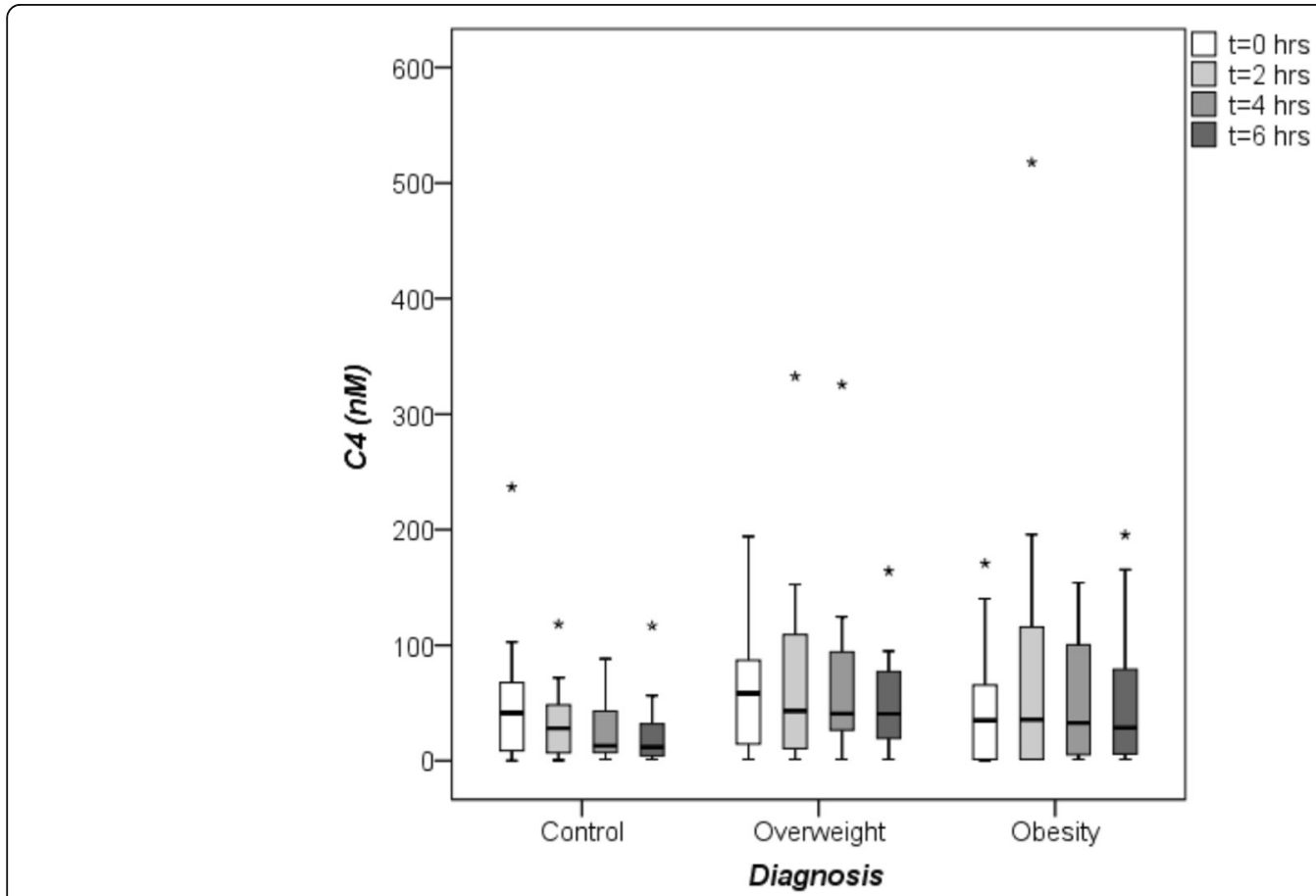

Fig. 4 Fasting and postprandial C4 concentrations. C4, a valid marker of bile acid biosynthesis, was measured by high-performance liquid chromatography (HPLC). Comparison of C4 values between healthy controls $(N=16)$, overweight $(N=14)$ and obese $(N=12)$ patients with non-alcoholic fatty liver disease (NAFLD) at baseline ( $0 \mathrm{~h}), 2,4$ and $6 \mathrm{~h}$ after the oral fat tolerance test (OFIT). C4 concentrations did not differ between groups (Kruskal-Wallis-test), ${ }^{*}$ outlier 


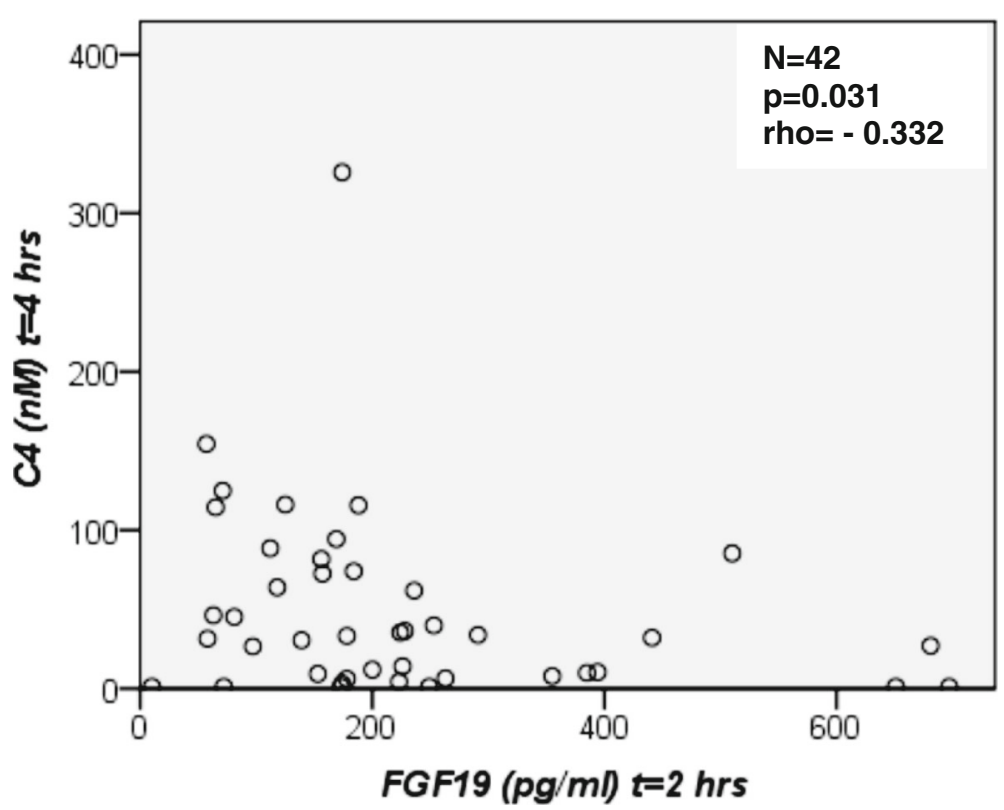

Fig. 5 FGF19 serum concentrations at $2 \mathrm{~h}$ versus $\mathrm{C} 4$ values at $4 \mathrm{~h}$ after the oral fat tolerance test (OFTT) for all subjects $(N=42)$. A scattered plot is shown and the Spearman's correlation coefficient was calculated

also an inverse correlation of FGF19 concentrations at $4 \mathrm{~h}$ and $\mathrm{C} 4$ values at $6 \mathrm{~h}$ after the OFTT in the study group (Fig. 6). These correlations were confirmed for the control group (Additional file 2: Figure S1, Additional file 3: Figure S2). In NAFLD patients, FGF19 concentrations did not correlate with $\mathrm{C} 4$ values.

\section{Discussion}

The present study investigated serum FGF19, BA, and C4 profiles in overweight and obese NAFLD patients, in comparison to normal-weight healthy controls, after a body weight-adjusted oral fat load. The key findings of our study are (i) fasting FGF19 concentrations were

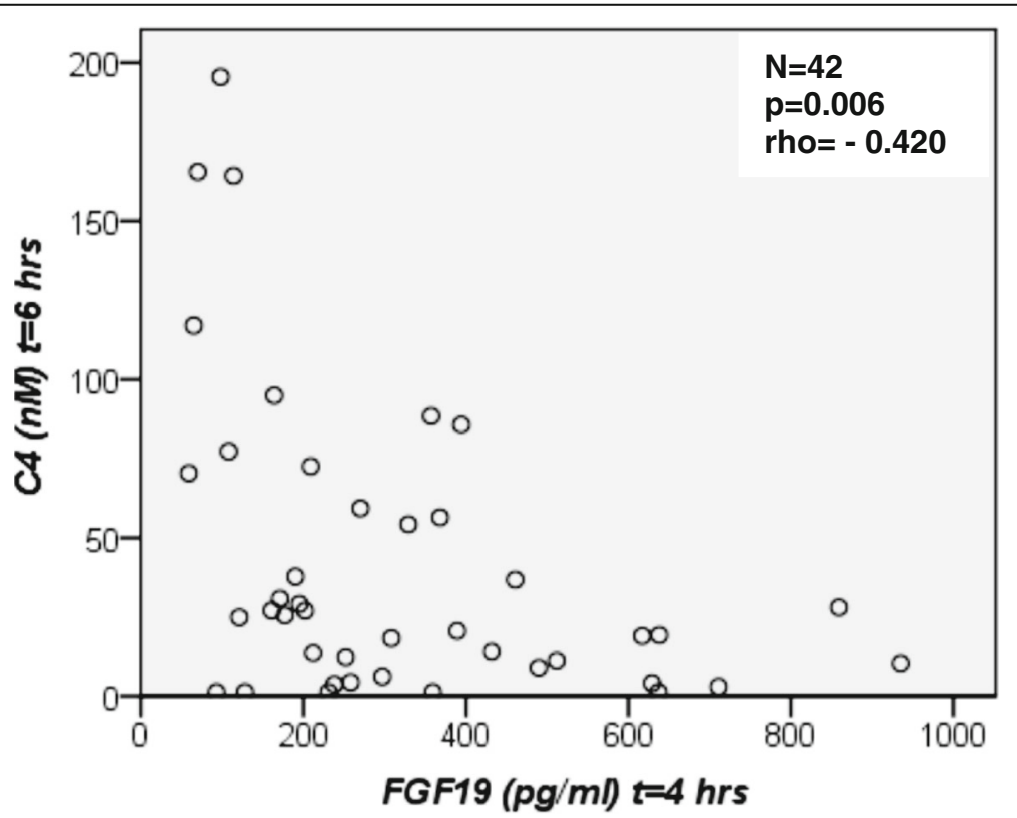

Fig. 6 FGF19 serum concentrations at $4 \mathrm{~h}$ versus $\mathrm{C} 4$ values at $6 \mathrm{~h}$ after the oral fat tolerance test (OFTT) for all subjects ( $N=42)$. A scattered plot is shown and the Spearman's correlation coefficient was calculated 
significantly lower in obese (grade II) NAFLD patients as compared to controls, (ii) overweight NAFLD patients had significantly lower FGF19 concentrations $2 \mathrm{~h}$ after the fat load and lowest values at all postprandial time points and (iii) BAs increased during the OFTT but without changes in $\mathrm{C} 4$ levels.

Low FGF19 concentrations have been reported in metabolic syndrome [35], obesity [36] and type 2 diabetes [37, 38]. The findings by Jansen et al. [19] support our results, i.e. the presence of fatty liver disease in obesity is associated with lower fasting FGF19 concentrations. Also in obese children with NAFLD [20] and young obese NASH patients [39] lower fasting FGF19 values were detected whereas Schreuder et al. did not observe differences in fasting FGF19 concentrations between controls and obese NAFLD subjects [13]. In our study, BMI correlated negatively with fasting FGF19 serum concentrations. Our study was too small to correlate FGF19 levels with biopsy-proven severity of NAFLD. In this respect, inverse associations had been found in children $[15,40]$, but some studies did not find correlations between steatosis grade and FGF19 concentrations [13, 14].

To the best of our knowledge, we are the first group which established a body-weight adjusted oral fat tolerance test (OFTT) to stimulate BA secretion and subsequent FGF19 expression in overweight and obese NAFLD patients. Only a few studies report about postprandial FGF19 concentrations [13, 41, 42]. Similar oral fat load tests have been used for determining postprandial triglyceride concentrations, but to date no standard method is established [43]. Our controls showed the highest FGF19 values during OFTT, suggesting unimpaired intestinal FGF19 release. Remarkably, overweight NAFLD patients had significantly lower FGF19 concentrations $2 \mathrm{~h}$ after the fat load as compared to controls and lowest hormone values at all postprandial time points. In another study in healthy volunteers, oral fat load (75 g vegetable fat, mixture of Calogen ${ }^{\circ}$, sun flower and olive oil) also showed a stepwise increase of FGF19 between 2 and $4 \mathrm{~h}$ and a decrease at $6 \mathrm{~h}$ almost reaching fasting levels [41]. Schreuder et al. used whipped cream for their oral fat test in NAFLD patients [13]. The fat challenge was applied with $30 \mathrm{~g}$ cream $(35 \% \mathrm{w} / v$ fat) per $\mathrm{m}^{2}$ of body surface area. Single postprandial time points in plasma FGF19 concentrations did not differ between controls and NAFLD patients. Interestingly, the postprandial FGF19-IAUC was lower in NAFLD patients [13]. In our study, mean AUC and IAUC did not differ significantly, but AUC was highest in controls and lowest in overweight patients; in contrast, IAUC was highest in obese and lower in overweight patients in comparison to controls. In comparison to Schreuder's study [13], our fat challenge was considerably higher, which could have contributed to differential findings at single postprandial time points and in FGF19-IAUC between controls and NAFLD patients.

Before our study started, we suspected that obese patients would have the highest energy and fat intake. Therefore we decided for a body weight-based fat load to adjust the OFTT to the patient's eating behavior. To check our assumption, we used a 3-day nutritional protocol and calculated energy and macronutrients intake (data not shown). Since there was no significant difference between groups, we suppose under-reporting of food intake in our overweight and obese patients. Most researchers agree that the reported accuracy of food intake decreases with increasing BMI. A systematic review covering studies between 1982 and 2014 showed that a BMI $>30 \mathrm{~kg} / \mathrm{m}^{2}$ is associated with significant under-reporting of food intake. These studies were mostly from Europe and North America [44]. For example, in morbid obese (BMI $>40 \mathrm{~kg} / \mathrm{m}^{2}$ ) energy intake can reach more than $4000 \mathrm{kcal} /$ day, with high fat intakes of about 40 to $57 \%$ of total energy intake [31].

In the present study, higher fat challenge in obese patients could explain their higher FGF19 values in comparison to overweight patients, which indicates that obese can compensate their low fasting FGF19 values by a high fat intake. Sonne and colleagues [42] found that FGF19 concentrations in patients with type 2 diabetes and healthy controls increased with increasing fat and decreasing carbohydrate content in liquid meals (500 kcal, 2.5 vs. 10.0 and $40.0 \mathrm{~g}$ fat). FGF19 values tended to be lower in type 2 diabetes patients compared with controls, but were not statistically significant.

Oral fat intake stimulates bile acid (BA) secretion. The entry of dietary fat in the duodenum causes gallbladder contraction and inflow of BA into the intestinal lumen. In the ileum, BA induce secretion of FGF19 that suppresses de novo BA synthesis in the liver [25]. In the present study fasting and postprandial BA concentrations did not differ between overweight/obese NAFLD patients and controls and $\mathrm{C} 4$ serum concentrations in NAFLD patients did not decrease as they did in controls. Therefore, the hepatic BA biosynthesis was presumably not repressed. One reason could be that CYP7A1 expression was insufficiently suppressed by FGF19 due to low fasting and postprandial FGF19 concentrations. Schreuder et al. [13] also reported an impaired hepatic response (no decline of C4) in NAFLD patients with insulin resistance. The pathomechanism(s) behind the observed blunted $\mathrm{C} 4$ response are unknown. One might speculate about impaired hepatic signaling after binding of FGF19 to the FGF receptor 4/ßKlotho heterodimer or other factors within the fatty liver cell that might affect the feedback regulation of BA synthesis. 
Our method of bile acid analysis did not yield complete profiles including conjugates with glycine or taurine. Thus, distinct differences in BA profiles between lean controls and NAFLD patients might have affected activation of FXR. This is supported by studies in Chinese children were levels of chenodeoxycholic acid (CDCA) were increased in the moderate/severe stage of NAFLD. The authors report, that decreased circulating level of deoxycholic acid (DCA) in children with mild NAFLD might have a negative effect on the activation of FXR, which subsequently triggers an increasing production of CDCA in patients with moderate to severe NAFLD [45]. In contrast, Jiao and colleagues [39] found increased DCA and decreased CDCA levels in NAFLD patients. In this context, changes in BA composition could also be one reason for altered intestinal FXR signaling, expressed as reduced FGF19 levels, in our overweight and obese NAFLD patients.

\section{Conclusions}

Fasting FGF19 serum concentrations were lowest in obese NAFLD patients and highest in normal-weight healthy controls. Our body weight-adjusted oral fat challenge resulted in lowest FGF19 concentrations in overweight NAFLD patients at all postprandial time points. Overweight and obese NAFLD patients showed impaired FGF19 release in fasting and postprandial state. We assume that obese NAFLD patients were able to compensate their low fasting FGF19 values by a high (body weight-adjusted) oral fat intake. Reduced FGF19 values in overweight and obese NAFLD patients might reflect altered intestinal FXR signaling. How the hepatic receptor FGFR4 or its cofactor $\beta$ Klotho modulate the hepatic response to FGF19 in NAFLD subjects should be examined further in functional studies.

\section{Additional files}

Additional file 1: Table S1. Prevalence of comorbidities in overweight $(N=14)$ and obese (12) NAFLD patients. In overweight NAFLD subjects, hypercholesterolemia is the dominant concomitant disease. In obese NAFLD patients, arterial hypertension, hyperlipidemia and hyperuricemia are the most common comorbidities. (DOCX $18 \mathrm{~kb}$ )

Additional file 2: Figure S1. FGF19 serum concentrations at $2 \mathrm{~h}$ versus C 4 values at $4 \mathrm{~h}$ after the oral fat tolerance test (OFTT) in controls $(N=16)$. (DOCX $36 \mathrm{~kb}$ )

Additional file 3: Figure S2. FGF19 serum concentrations at $4 \mathrm{~h}$ versus $\mathrm{C} 4$ values at $6 \mathrm{~h}$ after the oral fat tolerance test (OFTT) in controls $(N=16) .(D O C X 37 \mathrm{~kb})$

\section{Abbreviations}

BA: Bile acid; BMI: Body mass index; C4: 7a-hydroxy-4-cholesten-3-one; CDCA: Chenodeoxycholic acid; CYP7A1: Cholesterol 7a-hydroxylase: DCA: Deoxycholic acid; ELISA: Enzyme linked immunosorbent assay: FGF19: Fibroblast growth factor 19; FXR: Farnesoid X receptor; GC MS: Gas chromatography-mass spectrometry; HPLC: High-performance liquid chromatography; hrs: Hours; IQR: Interquartile range; NAFLD: Non-alcoholic fatty liver disease; NASH: Non-alcoholic steatohepatitis; OFTT: Oral fat tolerance test

\section{Acknowledgements}

We thank Nutricia $\mathrm{GmbH}$ for providing the study test drink Calogen ${ }^{\oplus}$ for our oral fat tolerance test (OFTT).

\section{Availability of data and materials}

The data sets analysed during the current study available from the corresponding author on reasonable request.

\section{Authors' contributions}

DF developed study design and OFTT, recruited study participants, measured body fat mass, centrifuged and aliquoted blood samples, performed FGF19 ELISA, analyzed the data and wrote the manuscript. FL developed the idea to investigate FGF19 serum levels in NAFLD. HUM measured BA and C4 concentrations. All authors read, edited and approved the final manuscript.

\section{Ethics approval and consent to participate}

The study protocol was approved by the Ethics Committee of the Ärztekammer des Saarlandes, Saarbrücken (ID number 58/09). All subjects ( $\geq 18$ years) were fully informed about the study objectives and methods and gave their written informed consent before participating in this non-randomized controlled pilot trial.

Competing interests

The authors declare that they have no competing interests.

\section{Publisher's Note}

Springer Nature remains neutral with regard to jurisdictional claims in published maps and institutional affiliations.

\section{Author details}

'Department of Medicine II, Saarland University Medical Center, Saarland University, 66421 Homburg, Germany. ${ }^{2}$ Department of Molecular and Clinical Medicine, Sahlgrenska Academy, Institute of Medicine, University of Gothenburg, Gothenburg, Sweden.

Received: 7 November 2016 Accepted: 23 May 2018

Published online: 04 June 2018

\section{References}

1. Mensink GB, Schienkiewitz A, Haftenberger M, Lampert T, Ziese T, ScheidtNave C. Overweight and Obesity in Germany: results of the German health interview and examination survey for adults (DEGS1).

Bundesgesundheitsblatt Gesundheitsforschung Gesundheitsschutz. 2013;56: 786-94.

2. Ogden $\mathrm{CL}$, Carroll MD, Fryar CD, Flegal KM. Prevalence of obesity among adults and youth: United States, 2011-2014. NCHS Data Brief. 2015;219:1-8.

3. Bellentani S, Scaglioni F, Marino M, Bedogni G. Epidemiology of nonalcoholic fatty liver disease. Dig Dis. 2010;28:155-61.

4. Kirovski G, Schacherer D, Wobser H, Huber H, Niessen C, Beer C, Schölmerich J, Hellerbrand C. Prevalence of ultrasound-diagnosed nonalcoholic fatty liver disease in a hospital cohort and its association with anthropometric, biochemical and sonographic characteristics. Int J ClinExp Med. 2010;3:202-10.

5. Paradis $\vee$, Bedossa P. Definition and natural history of metabolic steatosis: histology and cellular aspects. Diabetes Metab. 2008;34:638-42.

6. Cohen JC, Horton JD, Hobbs HH. Human fatty liver disease: old questions and new insights. Sci. 2011;332:1519-23.

7. Weinmann A, Alt Y, Koch S, Nelles C, Düber C, Lang H, Otto G, Zimmermann T, Marquardt JU, Galle PR, Wörns MA, Schattenberg JM. Treatment and survival of non-alcoholic steatohepatitis associated hepatocellular carcinoma. BMC Cancer. 2015;15:210.

8. Roeb E, Steffen HM, Bantel H, Baumann U, Canbay A, Demir M, Drebber U, Geier A, Hampe J, Hellerbrand C, Pathil-Warth A, Schattenberg JM, Schramm C, Seitz HK, Stefan N, Tacke F, Tannapfel A, Lynen Jansen P, Bojunga J. S2k-Leitlinie nicht alkoholische Fettlebererkrankungen. Z Gastroenterol. 2015;53:668-723. 
9. Graeter T, Niedermayer PC, Mason RA, Oeztuerk S, Haenle MM, Koenig W, Boehm BO, Kratzer W. Coffee consumption and NAFLD: a community based study on 1223 subjects. BMC Res Notes. 2015;8:640.

10. Hillenbrand A, Kiebler B, Schwab C, Scheja L, Xu P, Henne-Bruns D, Wolf AM, Knippschild U. Prevalence of non-alcoholic fatty liver disease in four different weight related patient groups: association with small bowel length and risk factors. BMC Res Notes. 2015;8:290.

11. Browning JD, Horton JD. Molecular mediators of hepatic steatosis and liver injury. J Clin Invest. 2004;114:147-52.

12. Postic C, Girard J. The role of the lipogenic pathway in the development of hepatic steatosis. Diabetes Metab. 2008;34:643-8.

13. Schreuder TC, Marsman HA, Lenicek M, van Werven JR, Nederveen AJ, Jansen PL, Schaap FG. The hepatic response to FGF19 is impaired in patients with nonalcoholic fatty liver disease and insulin resistance. Am J Physiol Gastrointest Liver Physiol. 2010;298:G440-G5.

14. Eren F, Kurt R, Ermis F, Atug O, Imeryuz N, Yilmaz Y. Preliminary evidence of a reduced serum level of fibroblast growth factor 19 in patients with biopsy-proven nonalcoholic fatty liver disease. Clin Biochem. 2012;45:655-8.

15. Alisi A, Ceccarelli S, Panera N, Prono F, Petrini S, De Stefanis C, Pezzullo M, Tozzi A, Villani A, Bedogni G, Nobili V. Association between serum atypical fibroblast growth factors 21 and 19 and pediatric nonalcoholic fatty liver disease. PLoSOne. 2013;8:e67160.

16. Jahn D, Rau M, Hermanns HM, Geier A. Mechanisms of enterohepatic fibroblast growth factor 15/19 signaling in health and disease. Cytokine Growth Factor Rev. 2015;26:625-35.

17. Tomlinson E, Fu L, John L, Hultgren B, Huang X, Renz M, Stephan JP, Tsai SP, Powell-Braxton L, French D, Stewart TA. Transgenic mice expressing human fibroblast growth factor-19 display increased metabolic rate and decreased adiposity. Endocrinol. 2002;143:1741-7.

18. Fu L, John LM, Adams SH, Yu XX, Tomlinson E, Renz M, Williams PM, Soriano R, Corpuz R, Moffat B, Vandlen R, Simmons L, Foster J, Stephan JP, Tsai SP, Stewart TA. Fibroblast growth factor 19 increases metabolic rate and reverses dietary and leptin-deficient diabetes. Endocrinol. 2004;145: 2594-603.

19. Jansen PL, van Werven J, Aarts E, Berends F, Janssen I, Stoker J, Schaap FG. Alteration of hormonally active fibroblast growth factors after roux-en-Y gastric bypass surgery. Dig Dis. 2011;29:48-51.

20. Wojcik M, Janus D, Dolezal-Oltarzewska K, Kalicka-Kasperczyk A, Poplawska K, Drozdz D, Sztefko K, Starzyk JB. A decrease in fasting FGF19 levels is associated with the development of non-alcoholic fatty liver disease in obese adolescents. J Pediatr Endocrinol Metab. 2012;25:1089-93.

21. Holt JA, Luo G, Billin AN, Bisi J, McNeill YY, Kozarsky KF, Donahee M, Wang DY, Mansfield TA, Kliewer SA, Goodwin B, Jones SA. Definition of novel growth factor-dependent signal cascade for the suppression of bile acid biosynthesis. Genes Dev. 2003;17:1581-91.

22. Kurosu H, Kuro-o M. The klotho gene family as a regulator of endocrine fibroblast growth factors. Mol Cell Endocrinol. 2009;299:72-8.

23. Kharitonenkov A. FGFs and metabolism. Curr Opin Pharmacol. 2009;9:805-10.

24. Inagaki T, Choi M, Moschetta A, Peng L, Cummins CL, McDonald JG, Luo G Jones SA, Goodwin B, Richardson JA, Gerard RD, Repa JJ, Mangelsdorf DJ, Kliewer SA. Fibroblast growth factor 15 functions as an enterohepatic signal to regulate bile acid homeostasis. Cell Metab. 2005;2:217-25.

25. Chiang JYL. Bile acids: regulation of synthesis. J Lipid Res. 2009:50:1955-66.

26. Kovár J, Lenícek M, Zimolová M, Vítek L, Jirsa M, Pitha J. Regulation of diurnal variation of cholesterol 7alpha-hydroxylase (CYP7A1) activity in healthy subjects. Physiol Res. 2010;59:233-8.

27. Deutsche Gesellschaft für Ernährung (DGE) e.V. Ernährungsbericht. Frankfurt: Deutsche Gesellschaft für Ernährung (DGE) e.V. 1992.

28. WHO. Obesity: preventing and managing the global epidemic. Report of a WHO consultation. World Health Organ Tech Rep Ser. 2000;894(i-xii):1-253.

29. Saverymuttu SH, Joseph AE, Maxwell JD. Ultrasound scanning in the detection of hepatic fibrosis and steatosis. Br Med J (Clin Res Ed). 1986; 292:13-5.

30. Nutricia GmbH. 2012. http://produkte.nutricia.de/de_de/pim/adults/ nahrungsmodule/calogen/1300/\#. Accessed 06 June 2012.

31. Harbury CM, Verbruggen EE, Callister $\mathrm{R}$, Collins CE. What do individuals with morbid obesity reportas a usual dietary intake? A narrative review of available evidence. Clin Nutr ESPEN. 2016;13:e15-e22.

32. Marschall HU, Wagner M, Zollner G, Fickert P, Diczfalusy U, Gumhold J, Silbert D, Fuchsbichler A, Benthin L, Grundström R, Gustafsson U, Sahlin S, Einarsson C, Trauner M. Complementary stimulation of hepatobiliary transport and detoxification systems by rifampicin and ursodeoxycholic acid in human liver. Gastroenterol. 2005;129:476-85.

33. Axelson M, Bjorkhem I, Reihner E, Einarsson K. The plasma level of 7 alphahydroxy-4-cholesten-3-one reflects the activity of hepatic cholesterol 7 alpha-hydroxylase in man. FEBS Lett. 1991;284:216-8.

34. Chan YH. Biostatistics 101: data presentation. Singap Med J. 2003:44:280-5.

35. Stejskal D, Karpísek M, Hanulová Z, Stejskal P. Fibroblast growth factor-19: development, analytical characterization and clinical evaluation of a new ELISA test. Scand J Clin Lab Invest. 2008:68:501-7.

36. Gallego-Escuredo JM, Gómez-Ambrosi J, Catalan V, Domingo P, Giralt M, Frühbeck G, Villarroya F. Opposite alterations in FGF21 and FGF19 levels and disturbed expression of the receptor machinery for endocrine FGFs in obese patients. Int J Obes. 2015:39:121-9.

37. Fang Q, Li H, Song Q, Yang W, Hou X, Ma X, Lu J, Xu A, Jia W. Serum fibroblast growth factor 19 levels are decreased in Chinese subjects with impaired fasting glucose and inversely associated with fasting plasma glucose levels. Diabetes Care. 2013;36:2810-4.

38. Roesch SL, Styer AM, Wood GC, Kosak Z, Seiler J, Benotti P, Petrick AT, Gabrielsen J, Strodel WE, Gerhard GS, Still CD, Argyropoulos G. Perturbations of fibroblast growth factors 19 and 21 in type 2 diabetes. PLoSOne. 2015;10:e0116928.

39. Jiao N, Baker SS, Chapa-Rodriguez A, Liu W, Nugent CA, Tsompana M, Mastrandrea L, Buck MJ, Baker RD, Genco RJ, Zhu R, Zhu L. Suppressed hepatic bile acid signalling despite elevated production of primary and secondary bile acids in NAFLD. Gut. 2017; https://doi.org/10.1136/gutjnl2017-314307. [Epub ahead of print]

40. Nobili V, Alisi A, Mosca A, Della Corte C, Veraldi S, De Vito R, De Stefanis C, D'Oria V, Jahnel J, Zohrer E, Scorletti E, Byrne CD. Hepatic farnesoid X receptor protein level and circulating fibroblast growth factor 19 concentration in children with NAFLD. Liver Int. 2017; https://doi.org/10. 1111/liv.13531. [Epub ahead of print]

41. Schmid A, Leszczak S, Ober I, Karrasch T, Schäffler A. Short-term and divergent regulation of FGF-19 and FGF-21 during oral lipid tolerance test but not oral glucose tolerance test. Exp Clin Endocrinol Diabetes. 2015;123:88-94.

42. Sonne DP, van Nierop FS, Kulik W, Soeters MR, Vilsbø\|l T, Knop FK Postprandial plasma concentrations of individual bile acids and FGF-19 in patients with type 2 diabetes. J Clin Endocrinol Metab. 2016;10:3002-9.

43. Mihas C, Kolovou GD, Mikhailidis DP, Kovar J, Lairon D, Nordestgaard BG, Ooi TC, Perez-Martinez P, Bilianou H, Anagnostopoulou K, Panotopoulos G. Diagnostic value of postprandial triglyceride testing in healthy subjects: a meta-analysis. Curr Vasc Pharmacol. 2011;9:271-80.

44. Wehling $\mathrm{H}$, Lusher J. People with a body mass index $\geqslant 30$ under-report their dietary intake: a systematic review. J Health Psychol. 2017: 1359105317714318. https://doi.org/10.1177/1359105317714318. [Epub ahead of print]

45. Lu LP, Wan YP, Xun PC, Zhou KJ, Chen C, Cheng SY, Zhang MZ, Wu CH, Lin WW, Jiang Y, Feng HX, Wang JL, He K, Cai W. Serum bile acid level and fatty acid composition in Chinese children with non-alcoholic fatty liver disease. J Dig Dis. 2017;18:461-71.

\section{Ready to submit your research? Choose BMC and benefit from:}

- fast, convenient online submission

- thorough peer review by experienced researchers in your field

- rapid publication on acceptance

- support for research data, including large and complex data types

- gold Open Access which fosters wider collaboration and increased citations

- maximum visibility for your research: over $100 \mathrm{M}$ website views per year

At BMC, research is always in progress.

Learn more biomedcentral.com/submissions 